\title{
Life-Experiences of Female Students in Physics: The Outsiders Within
}

\author{
Dagmar Heeg ${ }^{1 *}$, Lucy Avraamidou ${ }^{1}$ \\ ${ }^{1}$ University of Groningen, NETHERLANDS
}

Received 13 April 2021 • Accepted 10 June 2021

\begin{abstract}
The purpose of this multiple case study was to examine the kinds of experiences that were critical to the physics trajectories of four purposefully selected undergraduate female physics students in central Europe. The data were collected through individual semi-structured interviews and were analyzed following an inductive approach and a combination of open and in-vivo coding. The findings showed that: (a) all participants experienced a lack of sense of belonging in physics because of stereotypes and biases about the role of women in physics, which were evident both in classroom discourses and lack of recognition by their instructors and their male peers; (b) the intersection of gender and physics identity served as a barrier to the participants' perceived recognition (by others) as competent physics persons as well as their sense of belonging in physics; and, (c) all participants pointed to the lack of role-models and specifically women of color in academia.
\end{abstract}

Keywords: physics education, life-history, gender, case study

\section{INTRODUCTION}

With currently $37,3 \%$ of the students in science, technology, engineering, and mathematics (STEM) being female, the underrepresentation of women within STEM fields is still a current problem (European Commission, 2015). The Netherlands, which serves as the context of this study takes one of the bottom positions of the EU in terms of women in science research, with only 22,6 percent being female (Miller, Eagly, \& Linn, 2014). This underrepresentation does not only contribute to the general shortage of scientists in Europe (EC, 2015), but it also influences performance at the workplace. As research shows, gender diversity can contribute to creativity, productivity, innovation, and success in various ways (Blackburn, 2017). Barriers such as sexism and microaggression (Barthelemy, McCormick, \& Henderson, 2016), chilly working climates (Blackburn, 2017), and work environments in which women experience a lack of sense of belonging (Avraamidou, 2020) are a few reasons why women leave STEM fields. Through interventions, stronger recruiting manners, and mentor systems, attempts have been made to improve the participation of women in STEM (Blackburn, 2017). Despite these efforts, the gender gap in science still exists at a global level. The most striking example is the field of physics, in which women represent only 17 percent of the population of physicists (UNESCO, 2018). For this reason, physics serves as the context of this study.

To tackle the underrepresentation of women in STEM, a significant number of studies have been devoted to investigating possible causes of the lack of women in science in the past two decades. Researchers have adopted different theoretical lenses to examine various factors that influence women's participation in STEM including self-efficacy, self-view, identity, recognition, science capital, interest, and understanding of STEM careers (Avraamidou, 2020; Hazari et al., 2018). Other researchers examined how women, especially those belonging to minority groups (e.g., Black women, women of color, ethnic and religious minorities), have been traditionally excluded from science (HyaterAdams et al., 2019; Ong, 2005, Traxler et al., 2016). Blackburn (2017) found that women have to face multiple barriers such as biases, campus culture, classroom experiences, and stereotypes to pursue a career in STEM. Such barriers can be caused by institutional factors, such as conflicts between STEM expectations and institutional expectations towards women (Parson, 2018). At the same time, society causes barriers for women in science as well, for example by portraying and nurturing stereotypical ideas about

(c) 2021 by the authors; licensee Modestum. This article is an open access article distributed under the terms and conditions of the Creative Commons Attribution License (http://creativecommons.org/licenses/by/4.0/). 


\section{Contribution to the literature}

- The study addresses the issue of women's underrepresentation in physics through an examination of four purposefully selected undergraduate female students' life experiences that were critical to their physics trajectories.

- The findings of this study provide evidence of different factors that hinders female students' sense of belongingness in physics: gender-science stereotypes, lack of recognition, lack of diversity, and absence of role models especially of women belonging in minority groups.

- The implications of this study illustrate the importance of diversity within both study program and faculty, illustrating the importance of attracting and retaining women in academia that might serve as role-models for undergraduate students.

gender and science through the media (Gonzalez et al., 2017).

Several studies have provided evidence of the longstanding problem of women's underrepresentation in physics in the past decade (Gonsalves \& Danielsson, 2000). The findings of these studies show women's underrepresentation in physics is not an issue of interest or ability but an issue that relates to cultural stereotypes as well as structural and systemic issues (e.g., racism, sexism, organizational policies). Researchers provided evidence of the impact of sociocognitive factors, as for example, self-efficacy on female students' study and career choices (Kalender et al., 2020) as well as the support of faculty, research opportunities, and peer socialization (Nehmez \& Kelly, 2020). Besides the fact that physics remains the most male-dominated STEM field, it is also generally constructed as a masculine discipline (Gonsalves \& Danielsson, 2020; Francis et al., 2017). What this means essentially is that physics is perceived as a discipline more appropriate for men than for women. According to Francis et al. (2017) this is based on a variety of stereotypes such as associating femininity with superficiality and masculinity with cleverness. The problem with this, as Avraamidou (2020) argued, is that such associations imply that certain bodies and certain gender performances are excluded or are less accepted in specific spaces, such as in the world of physics. Therefore, women within the field of physics may face even more barriers than women in other STEM fields. As a set of studies have shown, women have been constructed as outsiders or positioned as 'Other' in physics because of their gender performativity (Archer et al., 2020; Gonsalves et al., 2014).

A review of the literature shows a gap in the literature in terms of life-history studies with university students as participants. Instead, the majority of related studies are either situated in specific timeframes: schooling, university, professional workplace, and using quantitative, large-scale approaches. In attempting to address this gap in the literature, this research aims to examine four undergraduate female students' life experiences that were critical to their physics trajectories. Gaining an understanding of these experiences, as well as the contexts in which they occur, can provide insights that are useful in examining women's underrepresentation in physics. More specifically, such knowledge can also be used as input for the design of gender-inclusive physics courses and teaching practices at the university level. Hence, the study was guided by the following research question: What kinds of life experiences did the participants perceive as critical to their physics trajectories?

\section{METHODS}

This multiple case study research aimed to examine critical experiences of four undergraduate female physics students which shaped their participation in physics. Comparing and contrasting the participants' experiences allow for an examination of how their unique identities serve either as barriers or bridges to their experiences in physics (Merriam, 2009). We interviewed four purposefully selected undergraduate women in physics. The participants were purposefully selected to maximize their diversity as a group in terms of kinds of identities: ethnicity, gender, race, religion, and social class). The four participants are all first- or second-year undergraduate physics students and between 19 and 22 years old at the time of the interviews. However, there exists diversity among them related to multiple identities: gender identity, racial identity, ethnic identity, social-class identity, and religious identity. For confidentiality purposes, pseudonyms are used, and some information that might have risk the anonymity of the participants is omitted. Table 1 provides an overview of the participants, their social positioning and their studies, and current place.

The data were collected through a one-hour-long semi-structured interview with each of the participants with the use of a validated protocol (Avraamidou, 2020). The interviews focused on extrapolating information about the participants' decision to study physics as well as the life experiences that they perceived a critical to their physics trajectories. The interviews were conducted in English or in Dutch depending on the participant's request. When was deemed necessary quotes were translated from Dutch to English. The Atlas software was used to analyze the interviews. We followed an inductive approach to the analysis and we used open 
Table 1. Participants' profiles

\begin{tabular}{ll}
\hline Participant & Social positioning \\
\hline Hanna & 20 years old \\
& Born and raised in Peru \\
& Middle-class family \\
& Caucasian (racially) \\
& Woman of color (culturally) \\
Kim & 20 years old \\
& Born and raised in central Europe \\
& Working/Middle-class family \\
& Caucasian \\
Loes & 20 years old \\
& Born and raised in Bahrain \\
& Working-class family \\
& Woman of color \\
& Muslim who performs her Islamic identity by \\
& wearing a hijab \\
& 19 years old \\
& Born and raised in India \\
Romy & Middle-class family \\
& Woman of color
\end{tabular}

Studies

Schooling in Peru

Second year undergraduate physics student, migrated from Peru to central Europe

Schooling in central Europe

First year undergraduate physics student in central Europe

Schooling in Bahrain

Second year undergraduate physics student, migrated from Bahrain to central Europe

Schooling in India

One year of undergraduate studies in physics, migrated from India to the US.

Currently a second-year undergraduate physics student, migrated from the US to central Europe

and in vivo, line-by-line coding techniques, using quotes and words from the participants as codes. Following that, we grouped the open codes into categories, as for example sense of self, recognition, role models, gender performance, etc. These categories were used as an organizational structure for the experiences that were perceived as critical by the participants. To establish trustworthiness, we used various triangulation strategies. We asked the participants to read our narration of their told stories and asked them to point out any inconsistencies in their stories or the interpretation of their stories. In addition, the two coauthors analyzed the data independently and they then discussed the outcomes until consensus was reached.

\section{FINDINGS}

\section{Hanna}

\section{Impact of high school teacher}

During high school, Hanna had a very high sense of competence as a learner. She was placed in the upper set, which was associated with the highest level in terms of achievement. This made her realize that she 'was better than the average student in her school'. However, despite her strong interest in physics, she didn't perceive herself as a physics person due to her gender. A high school teacher was able to change this mindset of hers:

My high school physics teacher had a really big influence for me to go study physics. Before I met him, I always had this idea that physics is only for boys. I'm a girl I shouldn't study physics. He managed to change my mindset and made me realize that I could do physics.

This excerpt provides evidence for stereotypical ideas that Hanna had about women being less capable in physics than men. When asked to reflect on these ideas, she traced them back to the culture of Peru, which is, in her words, is more of a patriarchal society. The excerpt shows how this teacher explicitly recognized her as a good physics student and illustrates how important this recognition has been for Hanna. Therefore, this excerpt provides evidence for the impact that high school teachers have on their students and their study interests.

\section{Gender, recognition, and sense of belongingness}

In high school, Hanna had to face the underrepresentation of women in science and specifically in physics. The underrepresentation of women caused feelings of exclusion for Hanna. In high school, she was often surrounded by male students. In her physics class, she was the only girl and during her math classes, there was only one other girl out of sixteen students total. As a university student, Hanna expresses some concerns about her not being recognized as a woman by her fellow male students:

I feel like I'm treated as one of the boys and not really as a girl. So, I do feel like that is different. Like, they don't see me especially as a female, they don't treat me as a female, but they are treating me as one of the guys.

This extract provides evidence of how women have to give up their gender identity to be accepted into a male-dominated environment and how their gender 
identity may not be recognized by men if they decide to keep it. Even though her fellow students may not recognize her gender identity, they do recognize her as a physics person. Even in high school, Hanna explains she was considered as one of the best of her class and they often asked her for help. Hence, her male classmates didn't show any signs of stereotypical thoughts regarding women in science, even though Hanna had these thoughts herself. What also strengthens Hanna her physics identity is seeing female teaching assistants and professors. Seeing them increases her sense of competence, proving to her that women can make a career out of physics:

I really like it when my teaching assistances and professors are females. It is kind of a positive influence. When I see them, I know it is manageable: they prove women can do it.

So far, Hanna had only seen a few professors, making her aware of the underrepresentation of women in physics. However, she does not necessarily perceive this as something negative she thinks it is an advantage to her:

I feel like being a woman studying physics has way more opportunities, because I feel like people are trying to encourage girls to go and study physics. So, if you are a girl, you have the advantage to get into better universities. You have the advantage to get into jobs which people wouldn't normally consider you. So, I feel like I have an advantage being a woman studying physics.

This excerpt implies that Hanna is not aware of the barriers the underrepresentation of women has caused her. Neither is she much affected by those barriers. This illustrates how women do not necessarily have to experience the same forms of hinder due to the interaction of their gender and physics identities. This finding related to Hanna is in line with the findings of Ong (2005) in which one of the participants expressed similar positive images to being a woman in a maledominated field. At the same time, this excerpt illustrates how Hanna, despite having feelings of exclusion and self-consciousness, sees being a woman in a male-dominated world as an advantage. This implies a strong science identity and a great amount of persistence in her physics trajectory so far. Moreover, this excerpt may imply that Hanna is not aware of possible inequalities women still encounter in the field of physics, specifically being undervalued for their work, getting paid less, and getting fewer opportunities for promotions or high valued positions (Lederman \& Bartsch, 2011).

\section{Kim}

\section{Impact parents and high school teacher}

Kim's family owns farms and one horseback riding school. Most of the farms have been in their family for multiple generations and Kim aspired to take over one of the farms from her father too. Therefore, she attended a specific type of high school to go to the farmer school. However, after two years she decided she wanted a bigger challenge and wanted to transfer to a different type of high school. During those years her interest in science grew. When she was trying to choose between studying astronomy or physics, a high school teacher explicitly encouraged her to choose physics:

I was in between astronomy and physics. But then my physics teacher said that physics was more for me. He said: It really fits you!

This extract provides evidence of the influence of a high school teacher. His explicit recognition of her as a good physics student and encouragement to study physics were important in Kim her choice for physics instead of astronomy. Kim was never encouraged by her family to go into science and didn't receive any support for her desired physics career. She has no contact with her mother and her father always steered her towards a career in farming. When Kim told her father that she wanted to go to the university to study physics, his initial reaction was negative:

My father wanted me to take over the farm. I wanted to take over the goat farm, but I also wanted to study. And I preferred studying. Initially, my father was mad about me wanting to study. Because we don't study within our family. But later he said: physics fits you. And now, although he doesn't like the fact that I don't live with him anymore, he is very proud that I'm studying.

An interesting phrase in this quote is the following: 'we don't study within our family'. When Kim was asked to elaborate on this, she explained that no one in her family attended university, partially due to financial reasons. Kim's decision to choose a career in physics instead of taking over a farm and therefore distancing herself from the family expectations might serve as evidence of her strong self-identification with physics.

\section{Sense of belongingness, gender performance, and competence}

As a first-year physics student, Kim feels included in the program. When she started her studies, Kim's biggest surprise was the 'high' number of female students. She thinks approximately ten percent of the students are females which she admits is not a lot, but still is a higher amount than she expected. When asked 
to reflect on whether the absence of women in her program influenced her, she said:

In high school, I had a group of friends with girls, but I would usually hang out with the boys. And now, my friends are mainly guys. Girls talk so much about make-up and stuff, that is not really my thing.

What is interesting to note in this quote is Kim her last comment which might imply that Kim has a less traditional feminine gender performance. In her words:

I don't like shopping; I prefer playing soccer. And some of my friends would want me to wear makeup when we go out, they even offer to do it for me, but I don't want that. They also think I should take better care of my hair, but I think a ponytail is already more than enough. And in general, girls don't like getting their hands dirty, while I prefer to immediately jump in the mud, so to speak.

This quote provides further evidence of Kim's less traditional gender performance and shows that Kim thinks her appearance and interests differ from the gender performance of a more typical girl. Having a less traditional gender performance might be seen as an advantage when studying physics, a field in which women are underrepresented. However, this is not the case for Kim:

I don't feel included when they say things like: Oh yeah, you are a girl. I think that is the most negative. 'you are a girl, so you wouldn't understand.' We often look at mems together and sometimes there are mems related to guys...Then I would say: just show it to me and explain it, so I understand it too. But they don't expect I will.

In this example, Kim feels excluded from a social instance within her group of (male) friends because of her gender. However, when asked to reflect on whether her friends ever used such phrases related to her study, Kim responded negatively. This implies that her male friends only question her competence in social situations and not concerning her physics study. Therefore, there is no clear sign of a lack of recognition of Kim as a physics person.

\section{Loes}

\section{Impact of parents, fellow high school students, and high school teachers}

Loes has always received a lot of support from her family to study science. She has two aunts with a background in chemistry who encouraged her and explicitly told her it was good she was doing physics. Loes shared that her mother knew she was going to study physics before she knew it herself:
My mum knew I was going to do physics before I knew I was going to do physics. Because, I really like drawing and she had this idea that an artist is also a physicist, because of Archimedes. And, so, she always associated people who like art a lot with people who like nature and physics. So, she was the one who kind of steered me towards physics mostly.

The verb 'steering' in this quote emphasizes the important role Loes' mother played in the development of her physics identity. When I asked Loes to reflect on this, she shared that it was her mother who encouraged her to take mathematics and physics courses in high school by reminding Loes of her love for logic and problem-solving. During high school, Loes' interest in physics was enhanced. Her initial negative attitude towards physics was based on the general opinion of her fellow students. Loes explains:

I remember that during the first year of high school, people would just say that physics is too complicated, physics is too hard and I don't like physics. Or, things like this are useless, what are we going to use the laws of motion for in the future or something like that. So, I was like yeah, this subject sucks! Because, initially, I didn't have an opinion. So, I just went with what people said.

When Loes had to choose a specialization, she decided to choose mathematics which meant she had to take physics as well. This decision led to her first physics courses and her passion for the subject started to grow. In her words:

The only subject that I genuinely liked was mathematics. So, I decided to tolerate physics so I could study mathematics. And then I was like: physics is cool. I enjoyed it and it became the thing that I was most passionate about, out of all the subjects.

It is interesting to note in this quote that Loes doesn't make any reference to her sense of competence but only refers to her passion for physics. After embracing her newfound passion for physics and deciding to study it, Loes engaged in discouraging conversations with her (female) high school teachers. They shared stories about their own experiences and how they all aspired to become researchers but instead ended up teaching:

When I told my physics teachers that I wanted to study physics, they were like: We also wanted to study physics and we also wanted to do our master's in physics. But we just ended up being teachers in Bahrain. Because there is no real developed physics research in Bahrain. So, they were like: If you don't want to be a teacher, don't study physics. And I knew that I liked the subject 
and the fundamental research that is going on, but I didn't want to end up doing just a high school teacher's job. So that is why I was kind of discouraged to study it.

This was a critical experience for Loes, who at that time, was considering migrating to central Europe where she thought she would be able to follow a research career in physics and not ending up like her high school teachers.

\section{Cultural barriers, gender, competence, and sense of belongingness}

Loes migrating to overcome this barrier of limited career options and to continue her physics trajectory is evidence for a strong physics identity. However, migrating to central Europe may have solved her first barrier, but it created a new one too: experiencing a sense of belongingness as a 'brown girl with a hijab' in physics, a field traditionally dominated by white men:

I was very, very nervous that I was going to be too different. I was kind of scared that it would be all white men in physics at the university and I would be the brown girl with the hijab being there. Maybe I am going there and my voice won't be heard or maybe people will discourage me when I say something.

This excerpt provides evidence of Loes' consciousness about her gender, race, and religion at the beginning of her studies and how it caused fear of being perceived as 'other'. At the same time, this excerpt provides further evidence for Loes being aware of existing gender inequalities in physics and how her different identities may form barriers in her physics trajectory. Especially the phrase 'maybe my voice won't be heard' expresses concern regarding her recognition as someone whose opinion mattered.

Going into a white male-dominated field, such as physics, did not only create a fear to be perceived as 'other' but also raised another cultural barrier: having to interact with men. Coming from a place where men and women normally don't interact a lot, this created feelings of discomfort for Loes at the beginning of her undergraduate program. In her words:

Where I come from, men and women don't interact a lot. I grew up with all-female teachers. I never had a male teacher. Maybe only in like a few, when I went to private institutes, that I had a few male teachers. So, I would say I was uncomfortable in my first year. But I grew to be more comfortable about it during this year.

In two years, Loes conveyed a sense of belongingness. When I asked her what factors or experiences have made her feel included, she attributes it to the overall diversity within the program and explains how this diversity has caused her to feel comfortable and included:

To see this much diversity was very different from what I had in mind and that is why it was very comfortable. And the diversity of the group that we were encouraged me to. I think if there was less diversity or I felt less included in events or programs or courses or in instances where we had group projects, I would feel more insecure. I think I would have been more likely to give up.

As a second-year physics student, Loes does not appear to be self-conscious of her gender, religion, or race anymore. During the interview, Loes shares that, so far, she has never had any negative experiences related to either of these identities. She thinks that people in central Europe are 'very nice and wouldn't 'point out such things as race and religion. Nonetheless, she is well aware of gender science stereotypes:

I guess I have noticed that sometimes when a female professor might make a mistake, there would be a group of people making fun of her. It is typical, but it is kind of annoying and that makes me aware. Like: what if I... I would hate to be in that position where I'm spoken badly about. And that makes me more aware of my situation. But otherwise, when...it feels normal. Like, maybe it doesn't mean that much what my gender is. But other times it is like: oh, yeah, I'm a female in physics.

This extract shows a few interesting things regarding gender identity. First of all, Loes imagining how similar bad things may happen to her in the future shows how she can easily identify with female professors. Moreover, it shows that Loes thinks the comments of the male students are because the professor is a woman and not just a bad professor. Secondly, the phrase 'that makes me more aware of my situation' proves Loes is normally not self-conscious of her gender, but negative experiences made her being more conscious about her gender. And last, the word 'typical' indicates how this experience confirmed her beliefs about the existing inequalities between men and women in physics. Although Loes observes how female professors are so few and are occasionally being made fun of students in the class, they still have an impact on her:

We only had a few female professors, but whenever I saw them teaching us, I was inspired. It was very encouraging to see women doing fundamental physics research.

Loes' emphasis on how 'seeing' women in physics doing interesting fundamental research encourages her, may indicate that she sees these women as role models. 
She also talked very enthusiastically about a female professor that she met with her mentor group:

There is like some sense of familiarity when a female approaches you. Yeah, I guess that it is just more comfortable and she was extremely welcoming and warm.

Interestingly, in this excerpt Loes emphasized how comfortable and familiar contact with another woman is, implying that interactions with men are not as comfortable. This might be related to the cultural differences as described before, related to Loes not being used to interact with men. But it may also illustrate how, in general, women have a different way of interacting than men, which is perceived as more comfortable by other women.

\section{Romy}

\section{Childhood science engagement, impact parents and high school teacher}

During her childhood, Romy was supported by her family to engage with science. Her most fond memories are the visits to a big science museum and planetarium. In the museum theoretical concepts from physics, such as centrifugal force, were explained in big interactive models. And in the planetarium, she saw rocket models and big fake planets. Reflecting on these childhood memories, she feels like these first encounters with science made a difference for her:

I think a lot of it started there. Otherwise, I don't think I would have thought of science that much. But because of all that I inclined towards physics and chemistry.

However, during middle school, Romy started getting conscious about her gender and it dissuaded her to pursue a career in science:

I didn't feel that my gender was stopping me to pursue a career in science till I got into my teens. For example, every time I answered questions from my physics teachers, they were like: Guys, you need to do something. This girl is doing better than you. It began like that and that is when I grew more conscious about my gender. When I moved to a different school, with much bigger classrooms, I heard these kinds of comments even more. The male peers around me who did not like it would say: You shouldn't do this, you shouldn't do that. And for half a year, I thought: maybe this isn't for me.

This quote illustrates how Romy's physics teachers had probably an unconscious bias towards female students. Moreover, it shows how Romy's male peers expressed superior feelings towards her and told her what to do and what not to do, specifically not to engage with science. Hence, both teachers and male peers didn't recognize Romy as a physics student. The excerpt provides evidence of how the lack of recognition as a physics person in high school can stand in the way of pursuing a physics trajectory, making Romy think science wasn't for her. Nonetheless, there was one high school teacher who explicitly recognized her as a good physics student, he appears to have played an important role in the development of Romy's physics identity. In her words:

The only person who supported me was my last physics teacher from my new school. He is incredibly sweet. He is the nicest person I know. And he was like: You should do science, you are really good at it. And I think he was also a very important person towards the end when it got harder to decide to go and study physics.

Besides encouraging Romy to pursue a career in physics, he also encouraged her to go abroad. When asked to elaborate on this, she explained that physics research is underdeveloped and underappreciated in India. When Romy expressed her desire to study physics abroad, she didn't receive much support from her parents, even though they have always supported her to engage with science. However, the lack of support from her parents, was, according to Romy, because of the lack of respect towards the field of physics in India. Her parents had, in her words, a lot of fear and resistance for the kind of life I would have in physics. Her mother would have preferred Romy pursuing an engineering career, which is a respected field. The wish of Romy's mother for her to become financially independent shows how cultural and financial barriers are of influence on Romy's physics trajectory. Nonetheless, Romy convinced her parents to allow her to study physics abroad. By making this decision, she had already crossed cultural and social class barriers.

\section{Race, gender, recognition, and sense of belongingness}

Romy started an undergraduate program at a university in the USA. But after a year, she decided to move to central Europa where she is currently a secondyear undergraduate physics student at a university. At the university, Romy her sense of belongingness is lower than in the US, but she still feels included. What makes her feel included in the diversity she sees within her program and especially her group of friends. Romy shares:

It helps seeing so many different kinds of people. All studying the same thing. I wasn't like an 'odd' person out. Because a lot of times I have been made to feel like being a brown girl going to academia is just wrong. But the simple fact that I get to see people who are like me, people who are 
different from the general group, makes me feel like I'm not weird.

This excerpt provides evidence of the impact of both gender and racial diversity on a sense of belonging for a woman of color. Secondly, Romy feels included when receiving recognition from teachers. She recalls receiving a compliment from one of her male teachers on getting a ten on a test and feeling included by that explicit recognition of her teacher.

What stands in the way of her sense of belongingness is the lack of recognition from male peers because of her gender. In her words, 'they often act like they are better than her, by correcting her homework for example. Moreover, a male peer student very explicitly questioned Romy as a physics person, asking her questions like: 'Are you sure you should be here in physics since you are a girl and stuff?' These are some of her most negative experiences as Romy explains. Such experiences are clear examples of the intersection of Romy her gender and physics identities. More importantly, it illustrates how this intersection of identities might cause a lack of recognition.

Romy's racial identity causes certain barriers for her. In the USA, where the undergraduate group was less diverse than in central Europe, she would have this feeling of 'eyes on me' and she would feel like she was 'standing out in the room' because of her black color skin. Romy explained this is also due to additional comments, expressing implicit racism, that she experiences: 'Indians are so smart' and 'Aren't Indians supposed to be good at this?'

Similar to other participants, Romy's interest in physics was enhanced through opportunities to interact with female physicists. Romy explains seeing female professors, makes her feel more certain that she can be successful in physics. Hence, the presence of female professors, with whom she can identify herself, increases her self-efficacy.

It is a matter of representation. I can look up to someone. And I find that representation in professors around me. It is always much easier when it is a female professor.

This excerpt illustrates how Romy can look up to female professors, implying they are role models to her. Moreover, Romy's phrase: 'much easier when it is a female professor' implies that she can more easily identify with female professors than with male professors. When asked to what extend she can identify with male professors of color, she stated that she identifies more with women:

I think it is because there is also the notion that professors, or any sort of authority, are intimidating and always associated with men. The moment you say professor, you think of a man. So, it is kind of a given that that one part is already easy for them. So, I don't feel as comfortable with male professors. There is always the feeling that: oh, this person thinks he is better than me, they are superior to me. You know, I'm smaller compared to them. But when I think of a female professor, that entire sculpt, that entire element is gone altogether. Because they feel more real, they feel more approachable.

Romy's description of professors always being male and intimidating are in line with existing literature related to gender and science stereotypes. However, even though coming across female professors encourages her, Romy stated that sometimes wishes she wouldn't have them, since she often sees them being disrespected by male students. Romy explains she notices that male peers of hers would joke more about female professors and would question if the female professors should be teaching them. Given that Romy aspires to become a professor herself, she describes these experiences as, in her words, 'the most demotivating experiences' she ever had, by showing her how much harder female professors have to work to earn respect.

\section{CONCLUSIONS}

The findings of this study show how all four participants have had unique, but also similar in some ways, experiences that were critical to their physics trajectories. The analysis focused on examining the impact of these experiences on their participation in physics. Although the participants have their unique trajectories and personalized experiences, specific themes have emerged that cut across the experiences that were perceived as critical to their life stories in physics.

\section{High School: Stereotypes, High School Teacher}

\section{Gender stereotypes hindering recognition}

Even though science is becoming more and more diverse, there are still stereotypical images of science and scientists. More specifically, physics is still considered a more masculine field (Francis et al., 2017). Moreover, there still exist general stereotypical thoughts, such as, women are less competent in science than men. Due to this stereotypical STEM profile, the perceived recognition of women and especially of those who belong in minority groups and of who don't fit this particular profile is hindered (Avraamidou, 2020). In line with this literature, the four participants shared experiences in which they were exposed to such stereotypical images during high school, by teachers, peer students, or family members. There were explicit instances, such as the comment 'you are a woman, people are not going to take you seriously' that one participant received, but there are also more implicit 
situations, such as a classroom experience of another participant in which the physics teacher showed a bias towards female students. The lack of recognition for the participants as physics persons, caused in most cases a decrease in their sense of competence too. In order words, lack of recognition due to stereotypical images of science and scientists has a significant impact on the physics identities, influencing two major components of it: recognition and competence.

\section{High school teachers as an important source of recognition}

The findings of this study show that all except for one participant had a high school teacher who played an important role in their physics trajectory. With Loes being an exception, these high school teachers were a positive influence. Loes' high school teachers discouraged her from pursuing a career in physics, explaining to her that there is little to no room for doing research but only for teaching when pursuing a physics career in Bahrain. For the other participants, such as Romy and Hanna, it was their physics high school teacher who explicitly recognized them as good physics students and encouraged them to pursue a career in physics. The participants all emphasized the importance of these high school teachers regarding their decision to pursuit physics. These findings are in agreement with literature that provides a wide range of evidence of the important role that high school teachers play in the development of female students' physics identities. Hazari et al. (2010) found, in their study with 3829 students, a positive correlation between encouraging teachers and strong physics identities. Moreover, Hazari et al. (2017) examined the role of high school experiences in the intention to pursue physics careers. By examining the time at which interest in physics career was generated for 900 female undergraduate physics students, they found a significant effect of high school physics teachers on the intention to pursuit physics after high school.

\section{University: Cultural Barriers, Gender Performance, Sense of Belongingness, Role Models and Classroom Activities}

\section{Cultural barriers to physics trajectories}

Except for Kim, all other participants migrated to the Netherlands for their undergraduate physics program. When I asked them why they chose this university, every single one of them described the university as affordable. They often compared the university with universities in the United Kingdom, which are very expensive. This illustrates how social class influenced their physics trajectory, which placed some universities financially out of reach. Moreover, Loes, Romy and Hanna, who all migrated from outside of Europe, mentioned a cultural barrier in relation to physics as well. In their home countries, Bahrain, India, and Peru, physics research is not very advanced and socially valued, as they explained. This forced them to choose between low valued and underpaid job positions, migrate, or give up their physics trajectory.

\section{Cultural barriers to physics trajectories}

One participant did not exhibit a traditional feminine gender performance. In simple words, her gender performances do not fit the 'girly girl' stereotype. In addition, her circle of friends consists of mostly men. Existing literature shows that women tend to adjust their gender performance, shifting from a feminine to a more gender-neutral or masculine performance to fit in the physics classroom (Danielsson, 2012; Ong, 2005). However, in the case of this participant, we would argue that her gender performances were not adjusted to the physics environment; instead, she exhibited less traditional feminine gender performances even before starting their physics programs. Nonetheless, she emphasized how her less feminine gender performance helps her connect with her male peers, confirming the existing literature about how a more masculine gender performance can nurture a sense of belongingness since it is closer to the expected masculine nature of science and masculine gender performances by scientists. Avraamidou (2020) who carried out a case study in which she investigated the multiple identities of a young Muslim immigrant woman in physics, observed similar behavior, in which her participant self-identified as an outcast because of her feminine gender performance in the male-dominated context of physics.

\section{Diversity and sense of belongingness}

The findings of this study show that diversity in the physics undergraduate program is one of the most important factors in nurturing a sense of belongingness. The participants observed a fair number of girls in their program and emphasized how it created a sense of belongingness. The two students of color emphasized the intersection of race and ethnic identities in the program, which addresses diversity factors that go beyond gender. They both argued that seeing people who differ from the 'average' in their program, makes them feel like they belong. Based on the findings of this study, visible diversity has such a significant impact on their sense of belongingness since they can easily identify themselves with other female students or persons of color. This is in agreement with literature that points to the fact that more diverse science learning environments support students to develop a sense of inclusivity and belongingness (Ong, 2005). 


\section{The impact of role models on competence and sense of belonging}

Various studies have shown that the positive effect of female instructors on physics performance and interest of female students is not significant (Bettinger \& Long, 2005; Hazari et al. 2013). However, the findings of this study implicate a significant impact on the competence and sense of belonging of female instructors. Three case studies illustrated receiving encouragement and confirmation of their abilities, by seeing other women succeed in the field of physics. The level to which the participants seem to identify with female professors imply that female instructors function as role models. Based on the findings it seems the participants receive this confirmation and sense of belongingness more from female than male instructors because they are from the same minority group. One participant, however, who finds herself more comfortable hanging out mostly with male students, was aware of the absence of female professors in her undergraduate program and didn't feel like this affected her in any way. This might imply how female students with a less feminine gender performance are less influenced by the presence of other women to receive a sense of belonging.

\section{Impact of classroom activities on interest and sense of competence}

The findings illustrate how explicit recognition increases the self-efficacy of students, by essentially offering them confirmation of their competence. As illustrated in the findings, this form of recognition is present at high school, often through a specific high school teacher. However, at the university, probably due to larger classrooms and less personal contact with instructors, such specific recognition is absent. Only one participant received explicit recognition from an instructor during her time at the university. Just like in high school, this had a positive impact on her selfefficacy. However, since feedback at the individual level is not typical in the university physics classroom which is typically large with the number of students up to 150 , we asked the participants what makes them feel confident and competent. They responded by referring to various situations that could all be traced back to classroom activities. Activities such as explaining the theory to peer students, performing experiments in the lab, and being able to respond to questions posed by the instructors, made the participants feel good about themselves and increased their self-efficacy. This is in agreement with existing literature, as for example, the study of Hazari et al. (2010) which examined the effects of different types of high school experiences on students' physics identities. One could argue, that such experiences are even more important in the context of university than high school, which tends to be a more impersonal place with few opportunities for individual attention because of the large classroom size.

\section{IMPLICATIONS AND RECOMMENDATIONS}

The goal of this study was to examine the kinds of experiences and events that were perceived as critical to the physics trajectories of four undergraduate female physics students in the Netherlands. The main conclusion drawn out of this study is that all participants felt like outsiders within as they experienced a lack of sense of belonging, lack of recognition, and exclusion from physics throughout their lives. In addition, the findings illustrated that the participants' experiences were filtered through different kinds of identity intersections, such as gender, ethnicity, social class religion, and race, proving the necessity of an intersectional lens while examining (non)participation in physics. Despite the uniqueness between these life stories, some similarities exist across the participants' stories: the intersection of gender and physics serves as the biggest barrier for the perceived recognition of the four undergraduate female physics students. Moreover, this intersection hinders the sense of belongingness academically, and incidentally socially as well given the fact that physics remains a male-dominated field.

For further research purposes, we would recommend an investigation into the lack of explicit recognition that female students experience at the university and how that impacts their perceived competence as physics learners. The influence of this lack of recognition on the sense of competence of female students remains unexplored in the literature. This holds promise given research evidence that reveals a positive correlation between self-efficacy and the performance of students (Rittmayer \& Beijer, 2008). Moreover, although some barriers such as cultural stereotypes are difficult to address and to tackle through short-term professional development programs, creating learning environments where female students do not only feel included but are also explicitly recognized as competent physics persons is of paramount importance.

The aim of this multiple case study was not to draw generalizable conclusions, but instead to construct an indepth understanding of the experiences of female students in the physics classroom throughout their schooling as well as their university education. The findings can be used as input for the design of genderinclusive physic courses and teaching practices. As an example of possible implications, the important role of high school teachers and discouraging effects of stereotypical images might be used as input to create gender-inclusive teaching practices in high school. Moreover, the findings of this study, as other studies have done (Archer, 2020; Gonsalves \& Danielsson, 2020, Hazari et al. 2018, Hayters et al. 2020) illustrate the importance of diversity within both study program and faculty, illustrating once more the essence of attracting and retaining more women in physics. These 
implications call for various actions at the university level to make physics more inclusive as follows:

- Provide professional development courses for all instructors around biases, racism, sexism, and exclusion in physics

- Provide diversity/inclusion training program for all physics instructors that will support them in enacting inclusive practices, curricular, and language of instruction

- Attract and retain female instructors and especially those belonging to minority groups (e.g., ethnic and religious groups) that might serve as role models

- Provide training for all instructors about the important role of explicit recognition for female students through active encouragement and individual attention

- Provide opportunities for female students to become members of support groups of students that nurture their sense of belongingness in physics (e.g., movie club for women in physics)

- Provide opportunities for female students to hear about female instructors' personal stories, women scientists' biographies, and to network with female professionals from a range of physics backgrounds and car

Author contributions: All authors have sufficiently contributed to the study, and agreed with the results and conclusions.

Funding: No funding source is reported for this study.

Declaration of interest: No conflict of interest is declared by authors.

\section{REFERENCES}

Archer, L., Moote, J., \& MacLeod, E. (2020). Learning that physics is 'not for me': Pedagogic work and the cultivation of habitus among advanced level physics students. Journal of the Learning Sciences, 29(3), 347-384. https:// doi.org/10.1080/10508406. 2019.1707679

Avraamidou, L. (2020). "I am a young immigrant woman doing physics and on top of that I am Muslim": Identities, intersections, and negotiations. Journal of Research in Science Teaching, 57(3), 311-341.

Barthelemy, R., McCormick, M., \& Henderson, C. (2016). Gender discrimination in physics and astronomy: Graduate student experiences of sexism and gender microaggressions. Physical Review Physics Education Research, 12(2), 020119. https://doi.org/10.1103/ PhysRevPhysEducRes.12.020119

Bettinger, E., \& Long, B. (2005). Do faculty serve as role models? The impact of instructor gender on female students. The American Economic Review, 95(2), 152157. https:/ / doi.org/10.1257/000282805774670149

Blackburn, H. (2017). The status of women in stem in higher education: A review of the literature 2007-
2017. Science \& Technology Libraries, 36(3), 235-273. https:/ / doi.org/10.1080/0194262X.2017.1371658

Blickenstaff, J. (2005). Women and science careers: Leaky pipeline or gender filter? Gender and Education, 17(4), 369-386. https:// doi.org/10.1080/095402505 00145072

Danielsson, A. (2012). Exploring woman university physics students 'doing gender' and 'doing physics'. Gender and Education, 24(1), 25-39. https:/ / doi.org/10.1080/09540253.2011.565040

European Commission. (2015). Science education for responsible citizenship. Directorate-General for Research and innovation, Science with and for Society.

Francis, B., Archer, L. Moote, J., DeWitt, J., MacLeod, E., \& Yeomans, L. (2017). The construction of physics as a quintessentially masculine subject: Young people's perceptions of gender issues in access to physics. Sex Roles: A Journal of Research, 76(3-4), 156174. https:/ / doi.org/10.1007/s11199-016-0669-Z

Gonsalves, A. J., \& Danielsson, A. (2020). Physics education and gender: Identity as an analytic lens for research. Springer. https:/ / doi.org/10.1007/978-3030-41933-2

González, D., Mateu, A., Pons, E., \& Domínguez, M. (2017). Women scientists as decor: The image of scientists in Spanish press pictures. Science Communication, 39(4), 535-547. https://doi.org/ $10.1177 / 1075547017719074$

Hazari, Z., \& Cass, C. (2018). Towards meaningful physics recognition: What does this recognition look like? Physics Teacher, 56(7), 442-446. https:/ / doi.org/10.1119/1.5055325

Hazari, Z., Brewe, E., Goertzen, R., \& Hodapp, T. (2017). The importance of high school physics teachers for female students' physics identity and persistence. Physics Teacher, 55(2), 96-99. https://doi.org/ $10.1119 / 1.4974122$

Hazari, Z., Potvin, Gl., Lock, R.M., Lung, F., Sonnert, G., Sadler, P.M. (2013). Factors that affect the physical science career interest of female students: Testing five common hypotheses. Physical Review Special Topics. Physics Education Research, 9(2), 020115. https://doi.org/10.1103/PhysRevSTPER.9.020115

Hazari, Z., Sonnert, G., Sadler, P., \& Shanahan, M. (2010). Connecting high school physics experiences, outcome expectations, physics identity, and physics career choice: A gender study. Journal of Research in Science Teaching, 47(8), 978-1003. https://doi.org/10.1002/tea.20363

Hyater-Adams, S., Fracchiolla, C., Williams, T., Finkelstein, N., \& Hinki, K. (2019). Deconstructing Black physics identity: Linking individual and social constructs using the critical physics identity framework. Physical Review Physics Education 
Research, 15(2), 020115. https://doi.org/10.1103/ PhysRevPhysEducRes.15.020115

Kalender, Z. Y., Marshman, E., Schunn, C. D., NokesMalach, T. J., \& Singh, C. (2020). Damage caused by women's lower self-efficacy on physics learning. Physical Review Physics Education Research, 16(1), 010118. https://doi.org/10.1103/PhysRevPhys EducRes.16.010118

Lederman, M., and Bartsch, I. (2001). The gender and science reader. Routledge.

Merriam, S. B. (2009). Qualitative research: A guide to design and implementation. Jossey-Bass.

Miller, D., Eagly, A., \& Linn, M. (2015). Women's representation in science predicts national genderscience stereotypes: Evidence from 66 nations. Journal of Educational Psychology, 107(3), 631-644. https:// doi.org/10.1037/edu0000005

Nehmeh, G., \& Kelly, A. M. (2020). Facilitating the selfdetermination of undergraduate women in physics: the role of external validation. Research in Science $\mathcal{E}$ Technological Education, 1-22. https://doi.org/ $10.1080 / 02635143.2020 .1740668$

Ong, M. (2005). Body projects of young women of colour in physics: Intersections of gender, race, and science. Social problems, 52(4), 593-617. https:// doi.org/10.1525/sp.2005.52.4.593

Parson, L. (2018). An institutional ethnography of higher education: The experiences of undergraduate women majoring in math and physics. Journal of Etnographyic \& Qualitative Research, 13, 18-33.

Rittmayer, A. D., \& Beier, M. E. (2008). Overview: Selfefficacy in STEM. In B. Bogue \& E. Cady (Eds.), Applying Research to Practice (ARP) Resources. https:/ / www.researchgate.net/publication/24258 9949_Overview_Self-Efficacy_in_STEM

UNESCO. (2015). Unesco science report: Towards 2030. United National Educational, Scientific and Cultural Organization.

\section{http://www.ejmste.com}

